Research Paper

\title{
Thermal behavior and kinetics assessment of ethanol/gasoline blends during combustion by thermogravimetric analysis
}

\author{
Luis Carlos Rios Quiroga ${ }^{\mathrm{a}, \mathrm{b}, *}$, José Antonio Perrella Balestieri ${ }^{\mathrm{a}}$, Ivonete Ávila ${ }^{\mathrm{a}}$

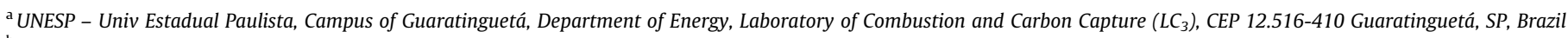 \\ ${ }^{\mathrm{b}}$ U.T.P. - Universidad Tecnológica de Pereira, Faculty of Mechanical Engineering, Pereira, Risaralda, Colombia
}

\section{H I G H L I G H T S}

- Kinetic parameters of thermal decomposition events were obtained.

- Thermal analysis was used as a tool for understanding combustion processes.

- Blends would be classified using thermogravimetric analysis technics.

- Synergistic effect of ethanol mixed with gasoline was studied and defined.

- Relative error and activation energy values were used to analyze the synergy.

\section{A R T I C L E I N F O}

\section{Article history:}

Received 6 September 2016

Revised 8 December 2016

Accepted 10 December 2016

Available online 12 December 2016

\section{Keywords:}

Synergy

Interaction

Thermal analysis

Free kinetics

Ethanol

\begin{abstract}
A B S T R A C T
The use of ethanol as a fuel or as an additive blended with gasoline is very important for most countries, which aim to reduce the heavy dependence on fossil fuels and mitigate greenhouse gases emission. An increased use of ethanol-gasoline blends has placed great relevance on acquiring knowledge about their physical and chemical properties. Thus, knowledge of such properties favors a better understanding of the effect of the percentage of ethanol/gasoline blends on engine performance. Thence, the present study has established a correlation between activation energy and synergetic effects, obtained by a thermal analysis, and ethanol content in gasoline for different blends in order to use this technique as a tool to classify these blends in the process in order to obtain useful energy in spark ignition engines. For such a purpose, a kinetic study has been conducted through a simultaneous thermal analysis system - TGA (thermogravimetry analysis) and DTA (differential thermal analysis) by following the methodology of non-isothermal tests. Thermogravimetric tests were performed and fuel activation energies for gasoline, ethanol, and percentages of $5,10,15,20,25,30,50$, and $75 \%(\% \mathrm{v})$ ethanol mixed with gasoline, which was achieved by the model free kinetics. The analysis results suggest that the theoretical curves characteristics of the thermal decomposition of ethanol-gasoline blends are rather different due to their ethanol content. Furthermore, it was observed significant interactions and synergistic effects, especially regarding those with low ethanol percentage. In conclusion, the thermal analysis techniques can be used as a tool for liquid fuel rating.
\end{abstract}

(c) 2016 Elsevier Ltd. All rights reserved.

\section{Introduction}

Energy is one of the most important factors that promote economic and industrial development. Fossil fuel combustion accounted for over $80 \%$ of primary energy use in the world in 2013 [1]. Global population growth has increased population mobility, and the production and consumption of goods, whose

\footnotetext{
* Corresponding author at: UNESP - Univ Estadual Paulista, Campus of Guaratinguetá, Department of Energy, Laboratory of Combustion and Carbon Capture (LC3), CEP 12.516-410 Guaratinguetá, SP, Brazil.

E-mail addresses: lcrios@utp.edu.co, lcriosq@gmail.com (L.C.R. Quiroga).
}

transportation means are considerable concerns as regards future energy strategies.

Oil cost variations and a desire to improve energy security in countries with limited oil resources are common concerns [2]. If compared to gasoline, ethanol has a greater octane number and latent heat of vaporization, which allows obtaining higher compression ratio and, consequently, increased thermal efficiency and a decrease in the emission of gases which are harmful to the environment [3]. Ethanol has a higher burning rate which can also help increase combustion efficiency and minimize energy loss [4,5].

Alcohols mixed with gasoline are interesting alternatives to reduce pollutant emissions and fossil fuel consumption. This is 
because they contain oxygen in their molecule, are highly volatile fuels, furthermore, blends with hydrated ethanol have small amounts of water in their composition, which allows reducing the temperature in the combustion chamber, thus improving efficiency and reducing the emission of NOx [6]. Moreover, lowcarbon alcohols (ethanol) lead to nearly zero particulate matter emissions [2]. These characteristics are generally favorable for good combustion.

Overall needs for both reducing the dependence on fossil fuels and mitigating greenhouse gases emission have led to seeking highly relevant knowledge in order to understand the ethanol content effect of ethanol-gasoline blends on their physicochemical properties and engine performance. In the short and medium term, ethanol mixed with gasoline is the biofuel with the greatest potential to be used worldwide in light passenger vehicles [6]. This scenario is due to the technology which has been used in current flexible fuel engines and small changes that must be made in conventional Otto cycle engines so as to adapt them to the use of lower ethanol content in gasoline, which may vary from $10 \%$ to $20 \%$ [7].

According to the development of future availability of ethanol scenarios in the United States, it was estimated that large increases from 4 to 7 points in gasoline RON (Research Octane Number) will be possible by increasing the ethanol content of the blend to $10 \%$ [8]. The use of ethanol-gasoline blends has become a reality in many countries, such as the United States, Brazil, Colombia, Thailand, India, China, and Canada [9]. which manufacture vehicles with flexible fuel technology in their internal combustion engines that can use blends with up to $85 \%$ (USA) and 100\% (Brazil) of hydrous ethanol or gasoline [7], while blends with low ethanol content require the use of anhydrous ethanol. All countries that have been using such blends have plans to increase the ethanol content in the gasoline, either as additive or fuel [9].

In pure fuels, a different set of reactions and chemical species must be determined individually in order to describe the reaction mechanism. Moreover, when different fuels are mixed, there may be cross-reactivity of intermediate species, which makes it necessary to include other additional reaction mixtures in the engine [10]. In addition, ethanol content in gasoline affects the vapor pressure of the fuel. Blends with low ethanol content, between $1 \%$ and $30 \%$, are more volatile than pure gasoline, and even more volatile than pure ethanol [11].

Particular interest should be given to knowing whether ethanol-gasoline blends have the same behavior as the one observed in the vapor pressure to obtain energy, as it would indicate the use of smaller quantities of gasoline in the blends with low ethanol content to obtain the same amount of energy. The previous behavior can be defined as the synergistic effect of ethanolgasoline blends.

It is considered the application of thermal analysis techniques, such as the thermogravimetric analysis (TGA) and differential thermal analysis (DTA) which have been widely accepted in the study of fossil fuels and biofuel combustion [12]. This technique has also been widely used to obtain the kinetic parameters of thermal decomposition events [13-17] and to conduct an analysis of the synergism between blends [18-21].

There are some studies in literature on thermal analysis to evaluate the synergism of solid fuel blends in the combustion of different blends, e.g. coal and biomass [18], biomass and plastic mixtures [19], oil shale semi-coke and torrefied cornstalk [20]. However, the study of synergism through liquid fuels is still little explored in literature, and works on the interaction effect on the thermal decomposition of ethanol-gasoline blends were not found ${ }^{1}$.

\footnotetext{
1 The key words used in the research were: Ethanol-gasoline blends, synergics, interaction, TGA, DTG.
}

In this context, the development of a methodology for testing ethanol-gasoline blends by using thermal analysis techniques in order to classify the blends according to their most important characteristics for the combustion process emerges as one of the main aims of this work. The thermal analysis can be used as a tool for understanding combustion processes, which is considered economic, quick and simple in comparison with other tests for fuel rating [22].

\section{Materials and methods}

\subsection{Sample preparation}

Gasoline type A (Table 1 ) is one produced by oil refineries, which is delivered directly to distributors without being mixed with ethanol. It is a mixture of naphtha in quantities that meet the product specification laid down by the ANP. The present work uses gasoline type $\mathrm{A}$, which was kindly provided by REVAP which is one of Petrobras refineries.

The term ethanol refers to ethyl alcohol that is marketed in two forms, hydrated (95\% to $96 \%$ ) and dry ( $\geqslant 99.5 \%$ ). The anhydrous ethanol (Table 1) used for the tests performed in this work was purchased from a commercial laboratory (Table 1 ).

The percentage proportion (\%) of ethanol in ethanol-gasoline blends is commonly preceded by the letter E, i.e. mixture E5 is composed of $5 \%$ ethanol and $95 \%$ gasoline (\%v). Samples of pure gasoline type A (E0), pure ethanol (E100), and their blends were used at a proportion of $5 \%$ to $75 \%$ ethanol to form blends E5, E10, E15, E20, E30, E50, and E75.

\subsection{Thermal analysis}

Thermal analysis experiments were performed through a TA Instruments high-resolution system (SDT Q600), which allows conducting TGA and DTA tests simultaneously. The thermogravimetric analysis (TGA) measures the weight loss of a sample as a function of increasing temperature, whose result is represented by the TGA curve (weight $\times$ temperature). DTG curve (derivative of the TG curve) represents the change rate in the sample weight. The differential thermal analysis (DTA) measures the temperature difference between a sample and a reference material as a function of temperature in the process of weight loss while samples and materials are being subjected to a controlled temperature program [23].

For high-volatility materials, mass measurement is critical and the initial sample mass for all tests should be with an amazing degree of accuracy. To improve its accuracy, a precision pipette $(10 \mu \mathrm{L})$ and a crucible with a lid were used. In addition, both the initial temperature of the test and the environment temperature were controlled. Initially, the sample was added to the crucible with a mass of around 5\% higher. Once the volatilization of the sample has reached the desired mass, the test was started.

Prior to testing, the samples were stored under refrigeration $5 \pm 0.5^{\circ} \mathrm{C}$ and the initial temperature of test was set at $18^{\circ} \mathrm{C}$. The

Table 1

Fuel properties of Brazilian gasoline type A and ethanol.

\begin{tabular}{lll}
\hline Properties & Ethanol $^{\mathrm{a}}$ & Gasoline $^{\mathrm{b}}$ \\
\hline Degree GL & 99.5 & 0 \\
Ant knock index (AKI) & 106 & 90.9 \\
Density & $0.79 \mathrm{~kg} / \mathrm{L}\left(20^{\circ} \mathrm{C}\right)$ & $0.743 \mathrm{~kg} / \mathrm{L}\left(20^{\circ} \mathrm{C}\right)$ \\
Lower heating value & $27 \mathrm{MJ} / \mathrm{kg}$ & $44 \mathrm{MJ} / \mathrm{kg}$ \\
Heat of vaporization & $904 \mathrm{~J} / \mathrm{g}$ & $346.7 \mathrm{~J} / \mathrm{g}$
\end{tabular}

a QUIMESP. Analysis report. Absolut alcohol.

b PETROBRAS. Analysis report. Certificate 2630 - 15 G. 
tests were conducted under an oxidant atmosphere of synthetic air under non-isothermal conditions from room temperature to $220^{\circ} \mathrm{C}$. Three different heating rates $\left(10^{\circ} \mathrm{C} / \mathrm{min}, 15^{\circ} \mathrm{C} / \mathrm{min}\right.$, and $20^{\circ} \mathrm{C} / \mathrm{min}$ ) were used under a dynamic atmosphere at a flow rate of $100 \mathrm{~mL} / \mathrm{min}$. Mass samples of $15 \pm 0.12 \mathrm{mg}$ and alumina crucible with a lid was adopted for all tests.

\subsection{Kinetic model}

The TGA techinique allows investigating the kinetics of thermal decomposition during the combustion of both solid [19,24-26] or liquid fuels [27-30]. The kinetics method applied in this study was based on isoconversional techniques and the activation energy was obtained as a function of the conversion level of a chemical reaction.

The kinetic decomposition analysis based on the use of model free kinetics allows obtaining information to calculate the activation energy $\left(E_{\alpha}\right)$ for a given conversion $(\alpha)[31,32]$. The conversion degree $(\alpha)$ is defined in terms of mass change in the sample, determined from the initial mass $\left(m_{0}\right)$, final $\left(m_{f}\right)$ and sample mass $(m)$ that varies with time (t), Eq. (1), all having been obtained from TGA curves.

$\alpha=\frac{\mathrm{m}-\mathrm{m}_{0}}{\mathrm{~m}_{\mathrm{f}}-\mathrm{m}_{0}}$

Under nonisothermal conditions, the temperature varies with a constant heating rate ( $\beta=\mathrm{dT} / \mathrm{dt}$ ) and Eq. (2) is obtained which is used to determine the activation energy for any conversion value $(\alpha)$.

$\ln \frac{\beta}{\mathrm{T}_{\alpha}^{2}}=\ln \left[\frac{\mathrm{RA}}{\mathrm{E}_{\alpha} \mathrm{g}(\alpha)}\right]-\frac{\mathrm{E}_{\alpha}}{\mathrm{R}} \frac{1}{\mathrm{~T}_{\alpha}}$

where $\mathrm{T}$ is the temperature, $\mathrm{R}$ is the universal gas constant, $\mathrm{A}$ and $\mathrm{E}$ are the Arrhenius parameters, and $g(\alpha)$ is the integral form of the reaction model.

With Eq. (2) $E_{\alpha}$ is obtained where the subscript indicates the activation energy related to a particular value of $\alpha$, given in $[\mathrm{kJ} /$ mol], $\beta$ is a given $[\mathrm{K} / \mathrm{min}]$ and $\mathrm{T}_{\alpha}$ is the temperature $[\mathrm{K}]$ relating to each $\alpha$ value.

For each $\alpha$ conversion value (0-1), a straight line is given by $\ln$ $\left(\beta / T_{2}\right)$ versus $\left(1 / T_{\alpha}\right)$, whose inclination is $-E_{\alpha} / R$, by the least squares method (Linear regression). For the application of the model, TGA tests must be conducted with at least three different heating rates [33]. The $\beta$ parameter and conversion curves are calculated from data obtained in the thermal analysis.

\subsection{Blends synergism}

The synergism can occur when mixing two fuels with different combustion characteristics, in which they can be improved, i.e. with one enhancing the physical or chemical combustion process of each other. In the thermal decomposition analysis, the concept of synergism is defined as the combined effect of two fuels being greater than the sum of each of them acting alone, though it can also be a negative effect, thus their combined effect will be less marked.

In order to identify the interactions between the components of the blends, their theoretical TGA curves were calculated as the sum of the weight loss curves of each individual component, Eq. (3) which was proposed by [18].

$(\mathrm{W})_{\text {Teo }}=\mathrm{x}_{1}(\mathrm{~W})_{\text {Ethanol }}+\mathrm{x}_{2}(\mathrm{~W})_{\text {Gasoline }}$

$\mathrm{W}$ is the weight loss of each fuel and $\mathrm{x}_{1}, \mathrm{x}_{2}$ are the volume proportions $(\% \mathrm{v})$ of ethanol-gasoline in the blend, respectively.

The above equation was also used to draw a theoretical data table for the activation energy by using the ethanol-gasoline data.
Eq. (4) defines the theoretical values of activation energy for ethanol-gasoline blends tested against conversion value $\alpha$.

$$
\left(\mathrm{E}_{\alpha}\right)_{\text {Teo }}=\mathrm{x}_{1}\left(\mathrm{E}_{\alpha}\right)_{\text {Ethanol }}+\mathrm{x}_{2}\left(\mathrm{E}_{\alpha}\right)_{\text {Gasoline }}
$$

The relative error $\Delta m_{\text {error }}$ in\%, proposed by [19], was used as a tool to quantify the possible interaction synergy when comparing the experimental (TGA curve) and theoretical (Eq. (4)) results of the blends TGA tests. It was calculated by using Eq. (5).

$\Delta \mathrm{m}_{\text {error }}=\left[\frac{\mathrm{m}_{\text {blend }}-\left(\mathrm{x}_{1} \mathrm{~m}_{1}+\mathrm{x}_{2} \mathrm{~m}_{2}\right)}{\mathrm{m}_{\text {blend }}}\right] \times 100$

where $m_{\text {blend }}$ is the weight loss of the blend, $m_{i}$ the weight loss of each material with the same operating conditions, and $\mathrm{x}_{\mathrm{i}}$ the volume fraction of each material in the mixture.

In the analysis of the synergistic effect of ethanol blended with gasoline on activation energy, it was used a relative error analysis tool, as defined in Eq. (6).

$\mathrm{E}_{\alpha \mathrm{error}}=\left[\frac{\mathrm{E}_{\alpha \mathrm{blend}}-\left(\mathrm{x}_{1} \mathrm{E}_{\alpha 1}+\mathrm{x}_{2} \mathrm{E}_{\alpha 2}\right)}{\mathrm{E}_{\alpha \mathrm{blend}}}\right] \times 100$

The error calculation proposed by Oyedun et al. [19], considers the variations in weight loss. However, the variation in temperature at which the maximum weight loss events occur in the sample is very important for the synergism analysis. Thus, it is also used Eq. (7) to calculate the relative error between the temperatures in the weight loss events when comparing the experimental (TGA curve) and theoretical results.

$\Delta \mathrm{T}_{\text {pico }}=\left[\frac{\mathrm{T}_{\text {pico-Teo }}-\mathrm{T}_{\text {pico-Exp }}}{\mathrm{T}_{\text {pico-Teo }}}\right] \times 100$

\section{Results and discussion}

\subsection{Fuel thermal analysis}

The thermal analysis of the fuel decomposition stages shows the TGA curves of the tests with the lowest heating rate ( $\beta=10^{\circ} \mathrm{C} / \mathrm{min}$ ). The choice of this heating rate was based on the fact that it is the most commonly found in literature on thermal analysis tests for liquid fuels [14-16,34]. It should be emphasized that the TGA/DTG curve behavior for other $\beta$ values are equivalent, thus modifying weight loss intensity, therefore obtaining higher peaks for greater values of $\beta$.

Fig. 1 shows the mass variation curves (TGA) and their derivative (DTG) as a function of temperature. It is observed in Fig. 1a that the DTG curve of gasoline has a long and low behavior, which indicates the volatilization variation of each of the fuel fractions, which occur sequentially and at different temperatures, i.e. starting at $25^{\circ} \mathrm{C}$ and ending at $200{ }^{\circ} \mathrm{C}$. Firstly, the volatilization of lighter fractions occurs, and then that of heavier fractions. In contrast, Fig. 1b shows the DTG curve of ethanol which, due to being a pure substance, its peak is narrow and intense, showing a high ethanol vaporization rate.

In order to evaluate the effect of ethanol on gasoline, it is presented a comparison of TGA/DTG tests for the two mixtures (E25 and E50) in Fig. 2. However, similar profiles were obtained for other studied blends.

As expected, it can be noted in Fig. 2 that there were two volatilization events for both blends, and each stage is finished once the volatilization curve returns to the baseline $(\mathrm{dW} / \mathrm{dt}=0)$ in the DTG curve, the former occurring at a temperature range of $18^{\circ} \mathrm{C}$ to $90^{\circ} \mathrm{C}$ and the later at a range of $90^{\circ} \mathrm{C}$ to $150{ }^{\circ} \mathrm{C}$, where the first one has a higher peak than the second one, i.e. the most intense peak is related to a greater speed mass loss due to the effect of ethanol on the mixture. A higher percentage of ethanol 


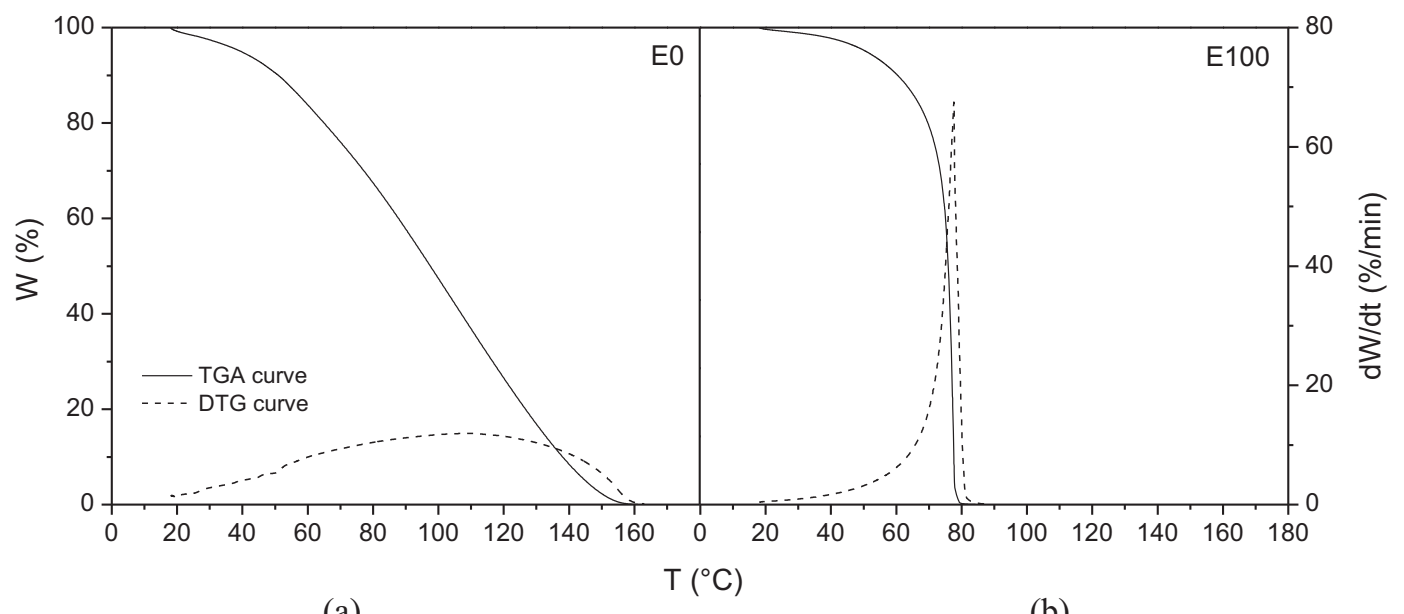

(a)

(b)

Fig. 1. TGA curves, weight loss (W) versus time (t), and DTG curves, dW/dt versus temperature (T) for (a) gasoline type A (E0) and (b) ethanol (E100): mass samples of $15 \pm 0.12 \mathrm{mg}$, synthetic air at $100 \mathrm{~mL} / \mathrm{min}$, and heating rate $10^{\circ} \mathrm{C} / \mathrm{min}$.

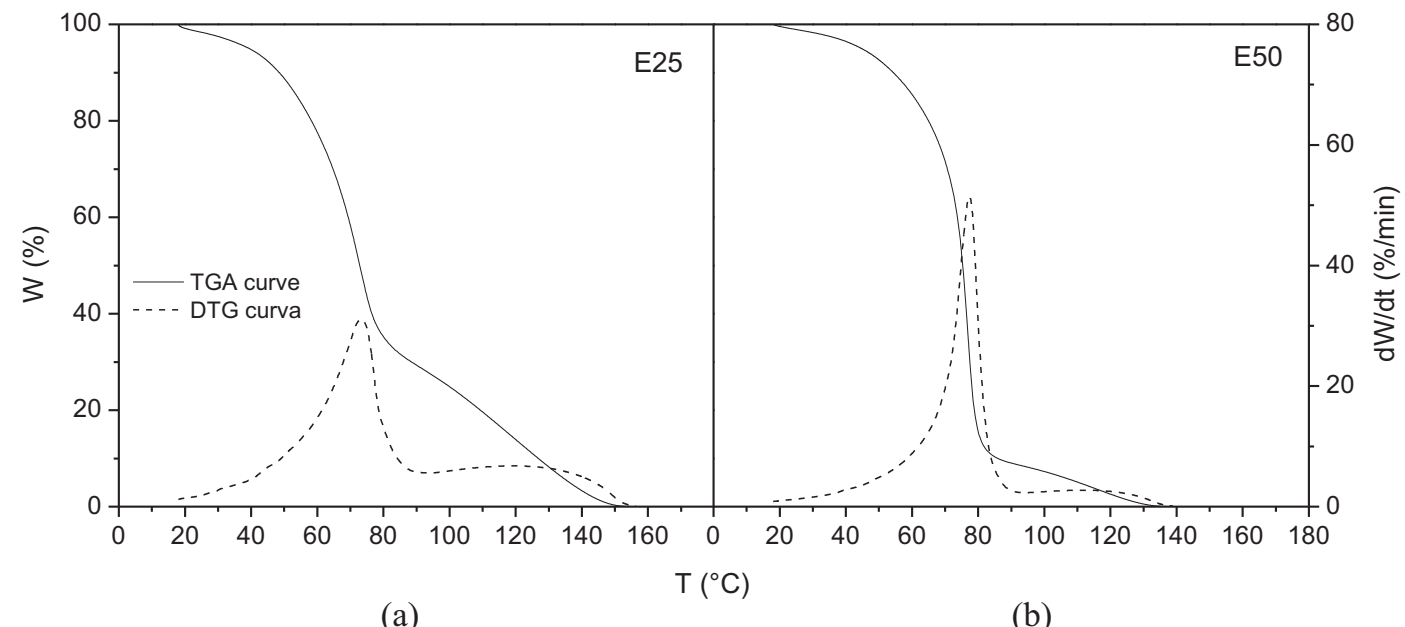

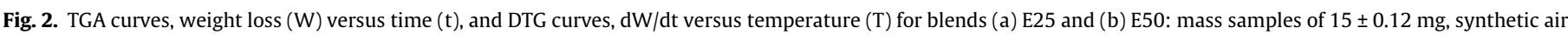
at $100 \mathrm{~mL} / \mathrm{min}$, and heating rate $10^{\circ} \mathrm{C} / \mathrm{min}$.

in the blend leads to a higher and narrower peak in the first stage, thus revealing the most predominant behavior of ethanol in the blend.

Fig. 3 shows the comparison of TGA/DTG tests for all ethanolgasoline blends, where it can be seen up to two thermal degradation stages characterizing the ethanol-gasoline blends.

It can be seen in Fig. 3 that the mixture with lower ethanol content has TGA/DTG curves which are similar to the one of gasoline, and as the amount of ethanol in the blend increases, the ethanol peak becomes more evident. It is noted that the TGA/DTG curves of blends E5 and E75 have a similar performance to pure fuels E0 and E100, respectively. The highest intensity peaks in the DTG curves that are characterized by narrower peaks are related to a higher volatilization rate which is directly proportional to the ethanol content in the blend.

Table 2 shows the initial and final temperatures as a function of volatilization ranges and peak temperature for ethanol, gasoline, and their blends

It is observed in Table 2 that blends E0, E5, E75, and E100 refer to tests in which the TGA/DTG curves have only one volatilization stage, which was expected in the case of pure fuels (E0 and E100). Blends E5 and E75 practically have one decomposition stage, thus it is very difficult to define where is the beginning or end of each of the two stages. Note, however, that in blend E5, there was a slight increase in peak temperature ( $3.7 \%)$ in comparison with E0, and blend E75 had an increase in the final temperature event ( $31.8 \%)$ if compared to E100, which shows the influence of the fuel at a smaller amount in the mixture. As regards the remaining blends, there was an increase in peak temperature due to an ethanol increase in the blend, thence greater weight loss rate which is proportional to the amount of ethanol in the mixture.

DTA curves are also shown in Fig. 3 in which $\Delta \mathrm{T}$ represents the temperature difference between both the sample and reference temperatures. The DTA curves evidence that there is only one endothermic transition stage for gasoline and its blends with ethanol due to fuel volatilization. The effect of the amount of ethanol on gasoline is similar to the behavior observed in the DTG curves, showing that the higher the ethanol content is, more intense the endothermic transition becomes.

\subsection{Chemical kinetics analysis}

Fig. 4 presents the TGA curves for three heating rates $\left(\beta=10^{\circ} \mathrm{C}\right)$ min, $15^{\circ} \mathrm{C} / \mathrm{min}$, and $20^{\circ} \mathrm{C} / \mathrm{min}$ ) for the pure fuels (E0 and $\mathrm{E} 100$ ) 


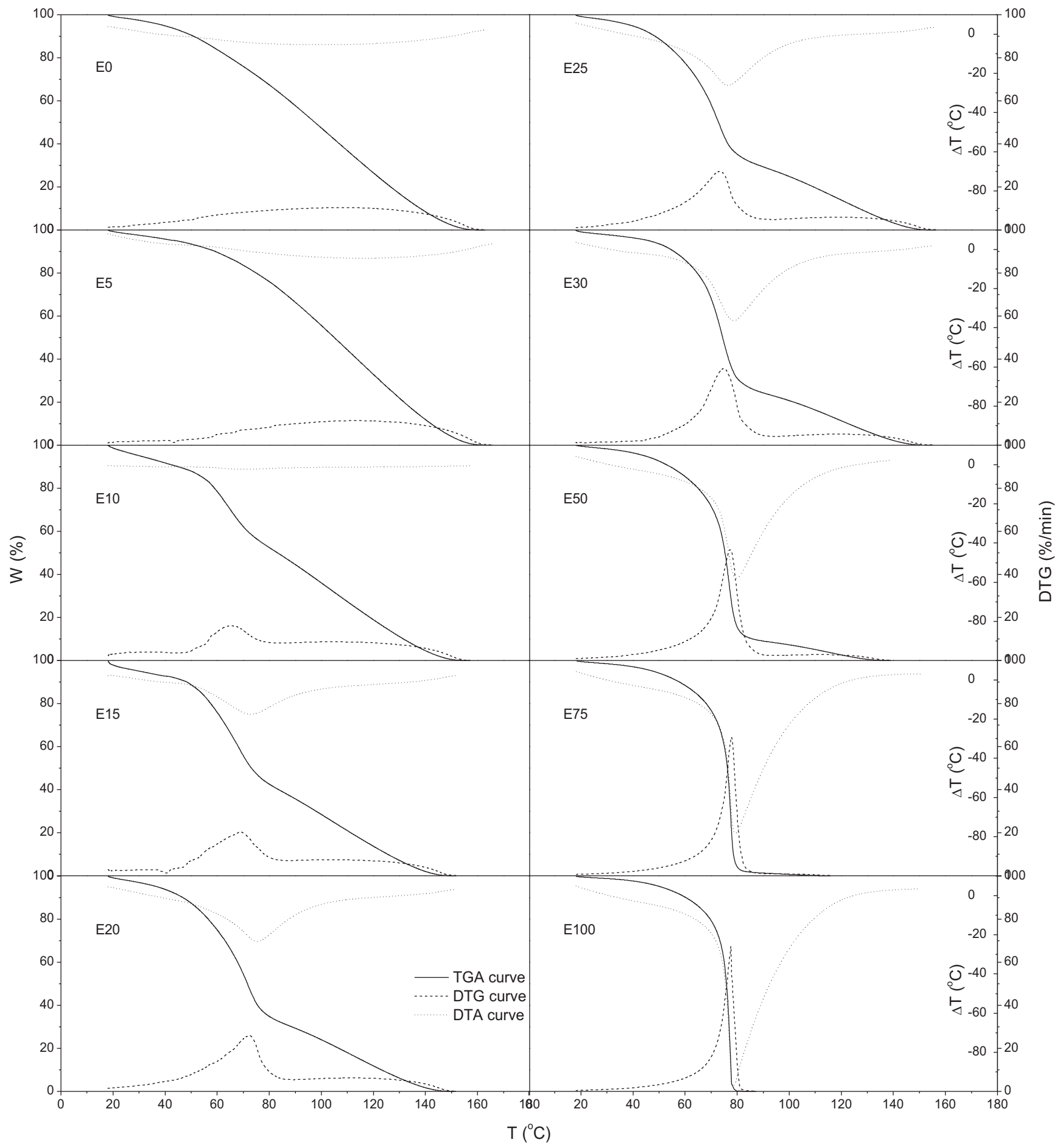

Fig. 3. Comparative TGA, DTG and DTA curves for all ethanol-gasoline blends: mass samples of $15 \pm 0.12 \mathrm{mg}$, synthetic air at $100 \mathrm{~mL} / \mathrm{min}$, and heating rate $10{ }^{\circ} \mathrm{C} / \mathrm{min}$.

and two blends (E25, E50). The other blends exhibited a similar behavior.

In Fig. 4, it is noted that an increase in heating rate leads to greater onset and final temperatures at which of the fuel volatilization occurs. In addition, it is observed that the conversion curves behavior is as expected, since the curve related to a heating rate of $15^{\circ} \mathrm{C} / \mathrm{min}$ is intermediate between the other two for all blends. It should also be emphasized that a change in heating rate does not lead to a variation in the temperature at which the process occurs. However, the speed at which the thermogravimetric analyzer can detect the weight loss varied, thus a displacement in the TG curves was observed.

Fig. 5 illustrates the kinetic analysis methodology applied to blend E25. For the kinetic study, the temperature at which there is a change in the baseline of DTG curve is considered as the one at the beginning of the volatilization event (Fig. 5a). The beginning of sample weight loss is indicated by the point at which the DTG curve leaves the baseline $(\mathrm{dW} / \mathrm{dt}=0)$ and the weight loss rate increases up to maximum speed rate (DTG peak). From this point on, there is a decrease in weight loss rate until the DTG curve 
Table 2

Temperatures and weight loss obtained from the blends tests.

\begin{tabular}{|c|c|c|c|c|c|c|}
\hline \multirow[t]{2}{*}{ Fuel } & \multicolumn{3}{|l|}{ Range 1} & \multicolumn{3}{|l|}{ Range 2} \\
\hline & Temperature range $\left({ }^{\circ} \mathrm{C}\right)$ & $\mathrm{T}_{\text {peak }}\left({ }^{\circ} \mathrm{C}\right)$ & Weight loss (\%) & Temperature range $\left({ }^{\circ} \mathrm{C}\right)$ & $\mathrm{T}_{\text {peak }}\left({ }^{\circ} \mathrm{C}\right)$ & Weight loss (\%) \\
\hline Gasoline (E0) & $18-165$ & 109 & 100 & - & - & - \\
\hline E5 & $18-165$ & 113 & 100 & - & - & - \\
\hline E10 & $18-84$ & 65 & 51 & $84-160$ & 104 & 49 \\
\hline E15 & $18-86$ & 69 & 59.9 & $86-154$ & 105 & 40.1 \\
\hline E20 & $18-87$ & 73 & 69.3 & $87-152$ & 111 & 30.7 \\
\hline E25 & $18-92$ & 73 & 722 & $92-157$ & 119 & 27,8 \\
\hline E30 & $18-93$ & 75 & 76.8 & $93-156$ & 119 & 23.2 \\
\hline E50 & $18-92$ & 77 & 93.6 & $92-138$ & 112 & 6.4 \\
\hline E75 & $18-112$ & 78 & 100 & - & - & - \\
\hline Ethanol (E100) & $18-85$ & 78 & 100 & - & - & - \\
\hline
\end{tabular}

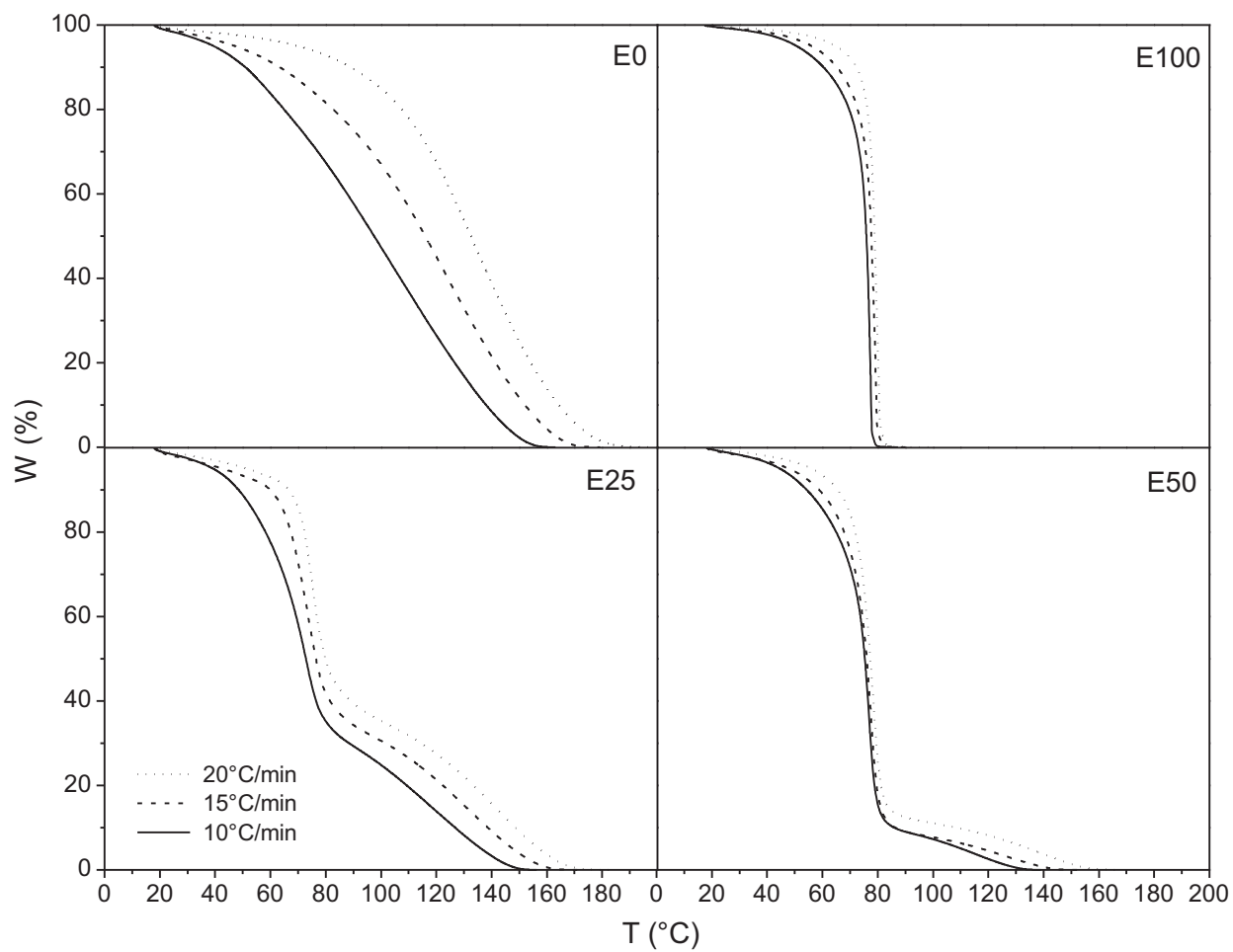

Fig. 4. TGA tests with three heating rates of $10^{\circ} \mathrm{C} / \mathrm{min}, 15^{\circ} \mathrm{C} / \mathrm{min}$, and $20^{\circ} \mathrm{C} / \mathrm{min}$; mass sample of $15 \pm 0.12 \mathrm{mg}$, and synthetic air at $100 \mathrm{~mL} / \mathrm{min}$.

returns to its baseline, thus indicating the end of the volatilization event.

From the TGA curves, the conversion is calculated by using Eq. (1). The conversion curves as a function of temperature for E25 sample is shown in Fig. 5b, in which it can be noted that for each value of $\alpha$ at different heating rates, a different temperature is associated. Through Eq. (2) and from the conversion values indicated in Fig. 5b, five straight lines were obtained for five $\alpha$ values $(\alpha=0.1,0.3,0.5,0.7$ and 0.9 ). The slope of each straight line in Fig. 5c represents the $E_{\alpha} / R$ for each conversion rate. The least squares method as a function of conversion rate was applied and $\mathrm{E}_{\alpha}$ values for E25 sample are shown in Fig. $5 d$, given that $\alpha$ values were calculated from $\alpha=0.1$ to $\alpha=0.9$ at intervals of 0.001 .

The same procedure described for E25 sample was applied to all other blends, whose results are shown in Fig. 6. In order to make a quantitative comparison, it was calculated the minimum, medium and maximum value of $\mathrm{E}_{\alpha}$. The measurement variation in Table 3 refers to standard deviation calculation for all $\mathrm{E}_{\alpha}$ values (from $\alpha=0.1$ to $\alpha=0.9$ ). It is observed in Fig. 6 and Table 3 that gasoline
(E0) has the smallest $E_{\alpha}$ values. Moreover, the addition of ethanol increases the activation energy.

The results presented in Table 3 are very interesting, because the ethanol content in the mixture is not proportional to the medium values of activation energy obtained. It can be seen that for low percentages of ethanol (up to 25\%) the results of activation energy are very close to the value of pure gasoline. It is also noted that the E20 mixture has the lowest medium value of activation energy, even a little below the value of pure gasoline. Activation energy increases dramatically for mixtures with higher percentages of ethanol, even above ethanol value. This shows a clear interaction of ethanol in the blend. The obtained activation energy values indicate that, among the evaluated blends, the best proportion of ethanol in the gasoline is possibly $20 \%$.

\subsection{Blends synergy}

In the synergism analysis, the theoretical curves were calculated by using Eq. (3). Fig. 8 presents the TGA curves for the blends 


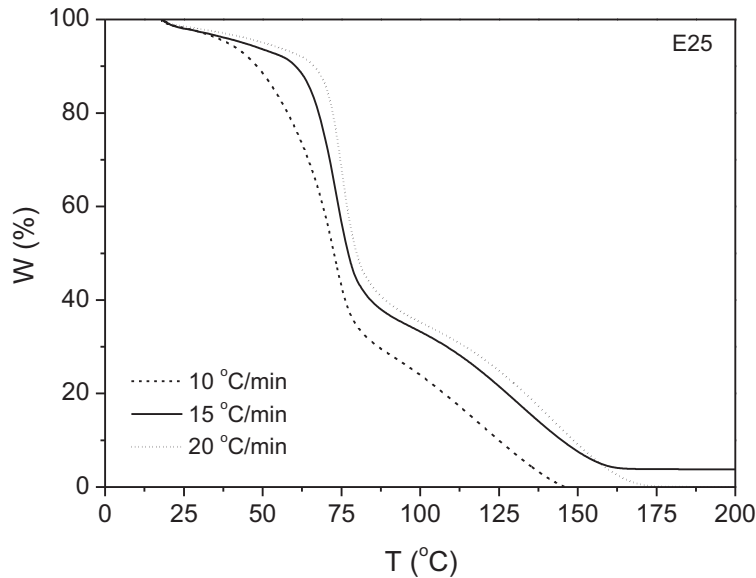

(a)

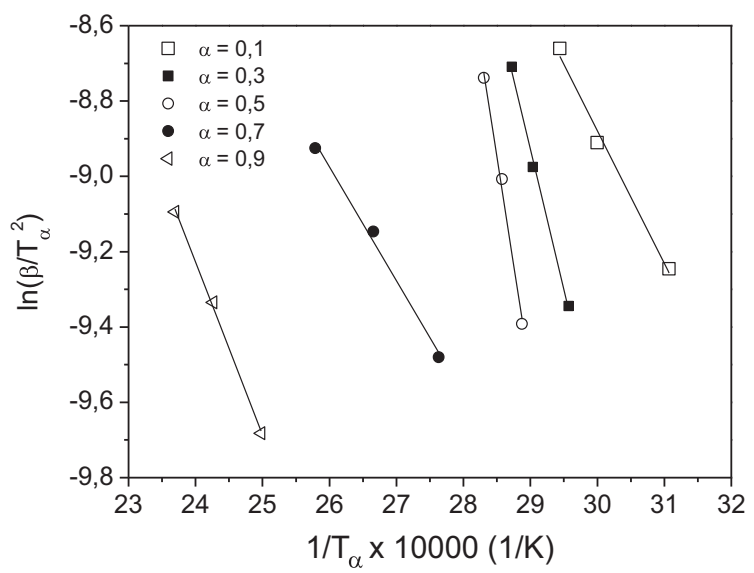

(c)

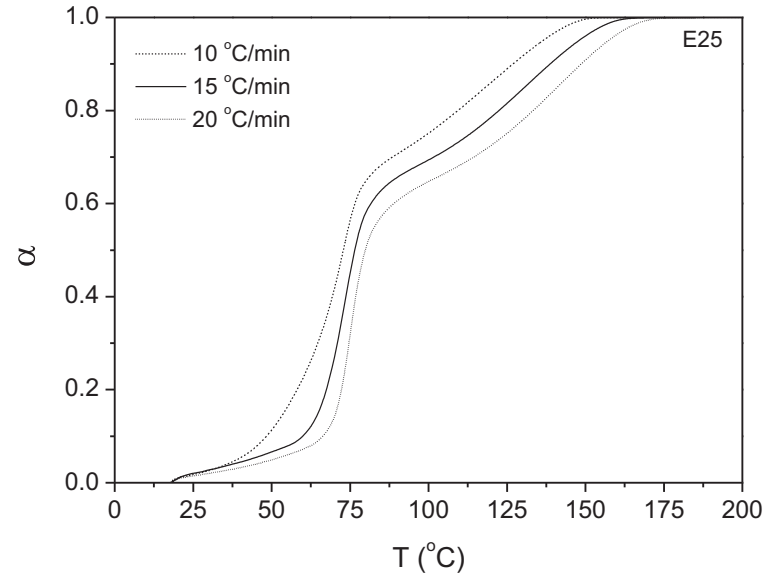

(b)

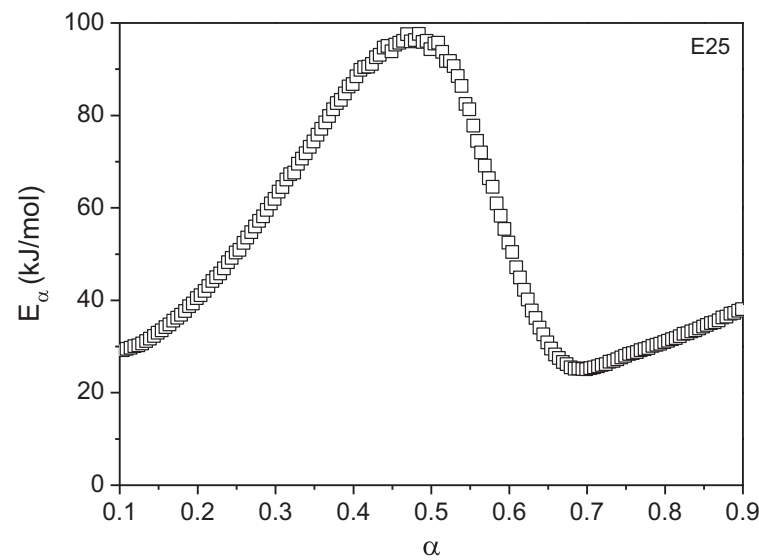

(d)

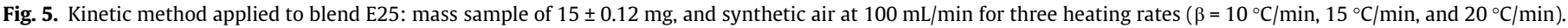

interaction analysis, where the magnitude of interaction is observed by comparing the differences in weight loss between the theoretical and experimental curves.

It can be seen in Fig. 7 that, for blend E5, the theoretical curve is below the experimental curve and the other blends have an opposite behavior. From blend E10, the weight loss events happen at higher temperatures in the theoretical curves until blend E75 whose weight loss temperature is the same in the theoretical and experimental curves. This behavior indicates the synergistic effect of ethanol in gasoline blends.

Peak temperature corresponds to a thermodynamic state where the largest thermal mass decomposition rate of a substance occurs in the thermogravimetric analysis. To better observe the temperature differences at which the events occurred in a comparison between theoretical and experimental curves, the DTG curves are presented for all blends in Fig. 8. The amount of synergy in the mixture is measured by the difference between the peak temperature of the experimental and theoretical curves.

In Fig. 8, it can clearly be seen that blends with low ethanol content shows a more notable synergy effect. The experimental curve for the thermal decomposition of blend E5 shows no peak temperature as compared with its theoretical curve. E50 and E75 blends did not show synergy as regards peak temperature.

Spark ignition engines require a fuel which vaporizes easily and is quickly mixed with air [2], and blends of ethanol-gasoline with low ethanol content vaporize well, as shown in Fig. 7. The property described above combined with the high flame speed of ethanol leads to a rapid ignition, thus resulting in increased pressure in the combustion chamber than gasoline, besides the increased power and lower emissions.

To determine the weight loss deviations between the theoretical and experimental curves in Fig. 7, and in order to quantify the synergism of ethanol-gasoline blends tests, it was used the error tool shown in Eq. (5). Table 4 shows results of relative errors for weight loss of the ethanol-gasoline blends.

The results presented in Table 4 show high synergism, with a deviation of up to approximately 51\%. Blends between E10 and E30 have the highest average and maximum values of synergism, which demonstrates the importance of ethanol in the blend for the thermal decomposition process. However, during the most important phase of thermal mass decomposition between $70^{\circ} \mathrm{C}$ and $75^{\circ} \mathrm{C}$, the weight loss rate is highest, and a large gap between experimental data and calculated data for each mixture is observed, especially regarding blends E10 to E20. The temperatures at which the maximum relative error is observed in various blends occur in a range of $70^{\circ} \mathrm{C}$ to $85^{\circ} \mathrm{C}$, with the exception of blends $\mathrm{E} 5$ and $\mathrm{E} 10$, where the temperature of the maximum error is lower $\left(25^{\circ} \mathrm{C}\right)$.

The maximum deviations, at temperatures between $70^{\circ} \mathrm{C}$ and $85^{\circ} \mathrm{C}$, can be attributed to ethanol decomposition characteristics if compared to gasoline. Due to its purity, ethanol decomposition occurs in a narrow range around $75^{\circ} \mathrm{C}$, while gasoline has a very broad range between $20^{\circ} \mathrm{C}$ and $180^{\circ} \mathrm{C}$, due to being a mixture of many compounds with different points of evaporation (see Fig. 1). 


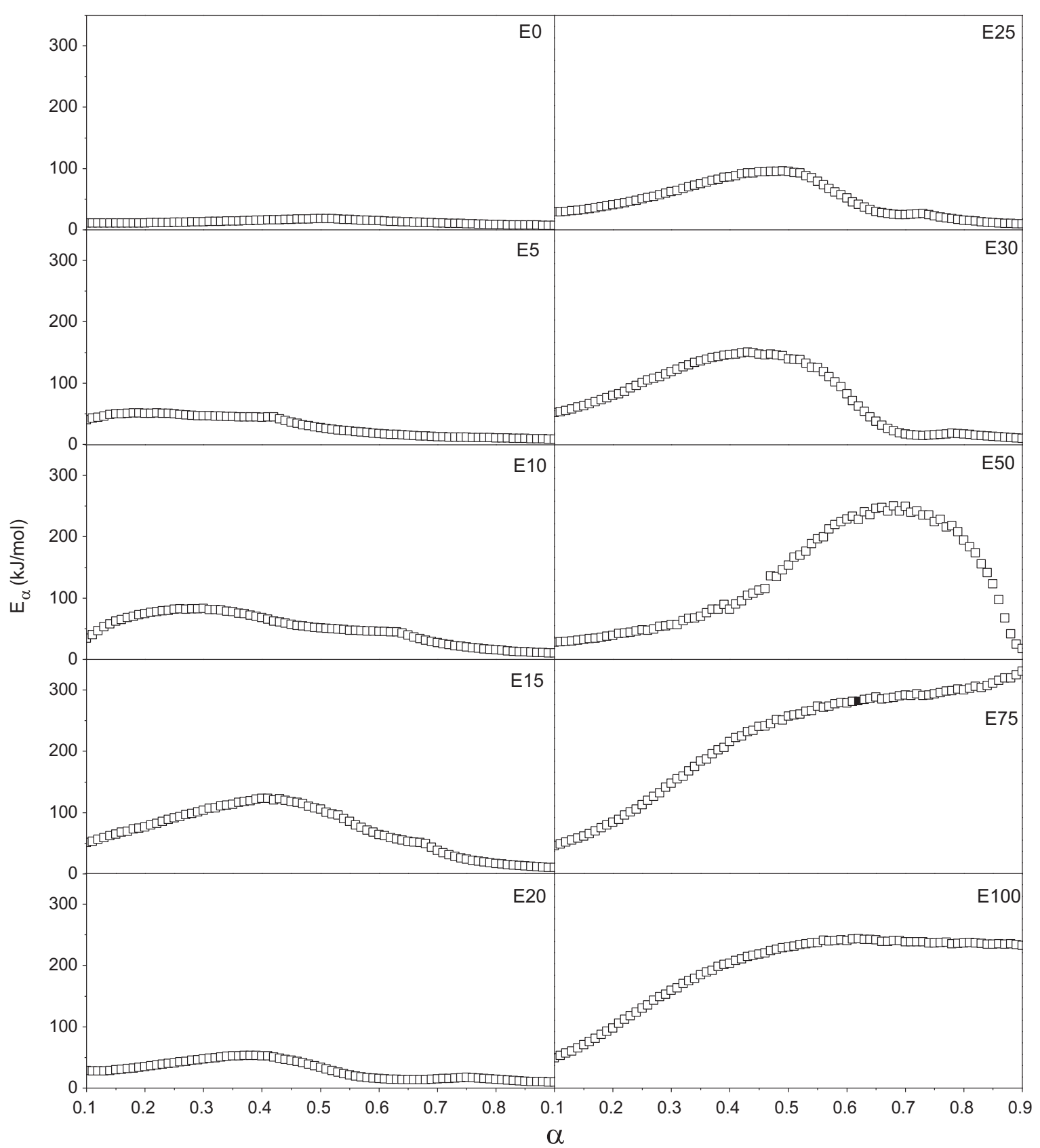

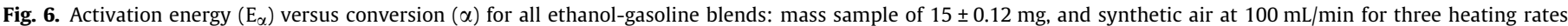
$\left(\beta=10^{\circ} \mathrm{C} / \mathrm{min}, 15^{\circ} \mathrm{C} / \mathrm{min}\right.$, and $\left.20^{\circ} \mathrm{C} / \mathrm{min}\right)$.

Table 3

Activation energy for the blends tested.

\begin{tabular}{|c|c|c|c|c|}
\hline \multirow[t]{2}{*}{ Blend } & \multicolumn{4}{|l|}{$\mathrm{E}_{\alpha}(\mathrm{kJ} / \mathrm{mol})$} \\
\hline & Minimum & Medium & Maximum & Measurement variation \\
\hline E0 & 22.06 & 28.12 & 43.20 & 6.58 \\
\hline E5 & 38.90 & 48.50 & 53.71 & 3.49 \\
\hline E10 & 29.64 & 47.85 & 80.73 & 13.47 \\
\hline E15 & 46.72 & 82.05 & 138.54 & 31.51 \\
\hline E20 & 13.33 & 27.28 & 53.40 & 13.23 \\
\hline E25 & 25.01 & 43.31 & 97.89 & 24.76 \\
\hline E30 & 14.50 & 78.98 & 150.60 & 48.75 \\
\hline E50 & 19.77 & 280.96 & 360.55 & 108.33 \\
\hline E75 & 46.07 & 257.33 & 340.44 & 86.75 \\
\hline E100 & 49.38 & 230.78 & 245.53 & 59.74 \\
\hline
\end{tabular}




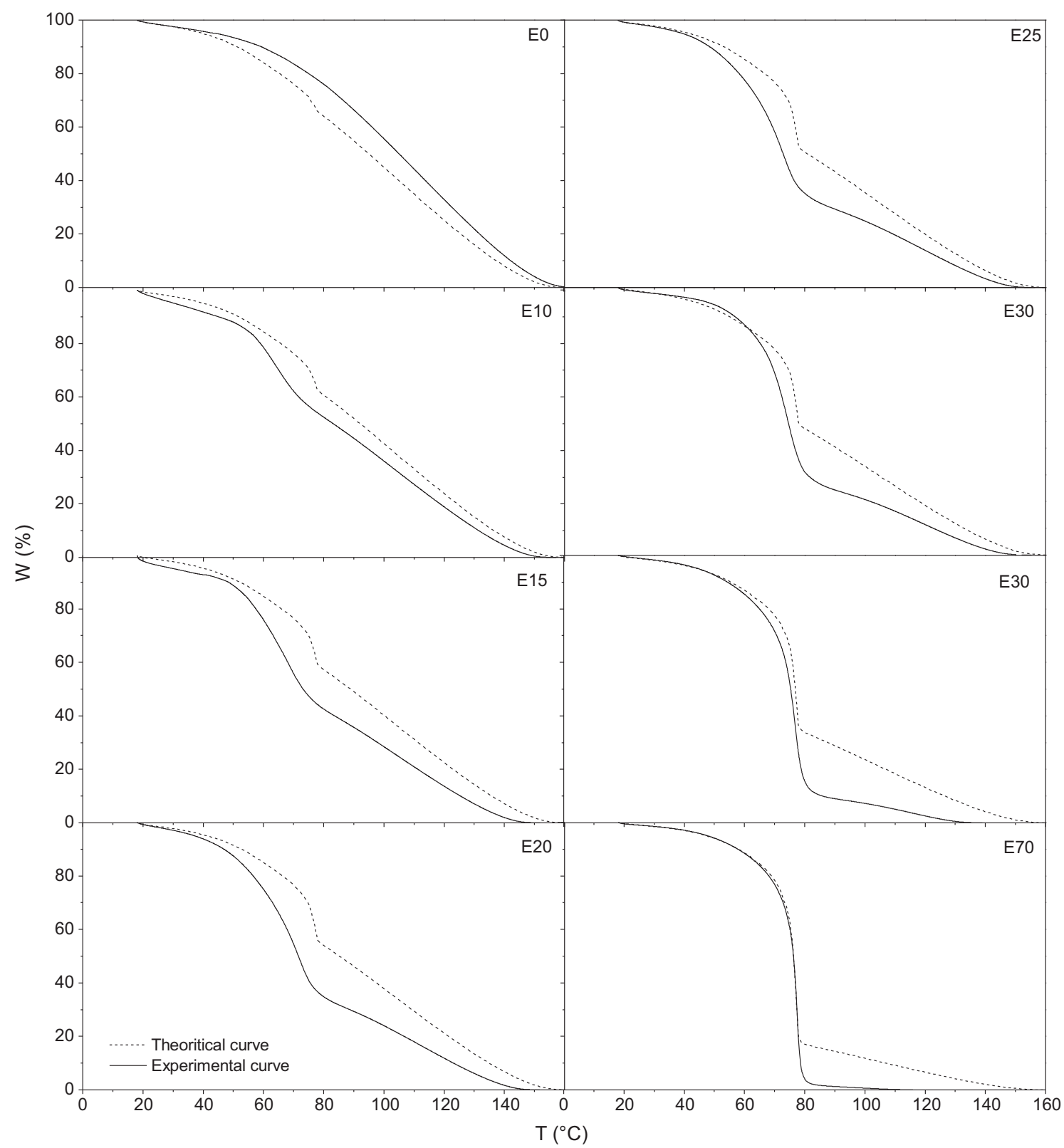

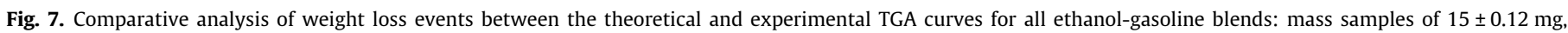
synthetic air at $100 \mathrm{~mL} / \mathrm{min}$, and heating rate $10^{\circ} \mathrm{C} / \mathrm{min}$.

By using Eq. (7) in the interaction of theoretical and experimental DTG curves, the synergy of peak temperature can be known quantitatively. The measurements of the interaction of ethanol with gasoline for all blends tested are shown in Table 5 .

From Table 5, it can be observed that E10 presents the highest percentage of synergy with peak temperature. E10 possesses a lower peak temperature in experimental curve at $16.17 \%$ if compared to the theoretical peak temperature. The percentages described as an interaction indicate that the synergy is lower when ethanol content is greater in the gasoline blend.

As it can be seen in Fig. 8, the experimental curve has no peak, thus it cannot have peak temperature data that serves as a way to calculate the interaction percentage shown in Table 5.

It was used the activation energy values in Table 3 and Eq. (4) to obtain the theoretical activation energy data for each of the tested blends. By comparing the theoretical and experimental activation energy data by means of Eq. (6), it is obtained the relative error of activation energy for all tested ethanol-gasoline blends, as shown in Table 6. For the interaction analysis of the activation energy of ethanol-gasoline blends, it is considered the negative error as synergy. This is because smaller activation energy values leads to better performance in the combustion process. It should be highlighted that the data obtained for blends between E20 and E30 where the highest values of synergy were obtained, both medium and maximum error.

The analysis of the blends kinetics indicates that small increases in the percentage of ethanol, low percentage terms, leads to reduced activation energy for the decomposition reaction in the range of high conversion values between 0.6 and 0.8 . Subsequently, the activation energy increases for small conversion values. For blends with ethanol content of less than $30 \%$, their behavior is completely different from high content blends. The mixture with 


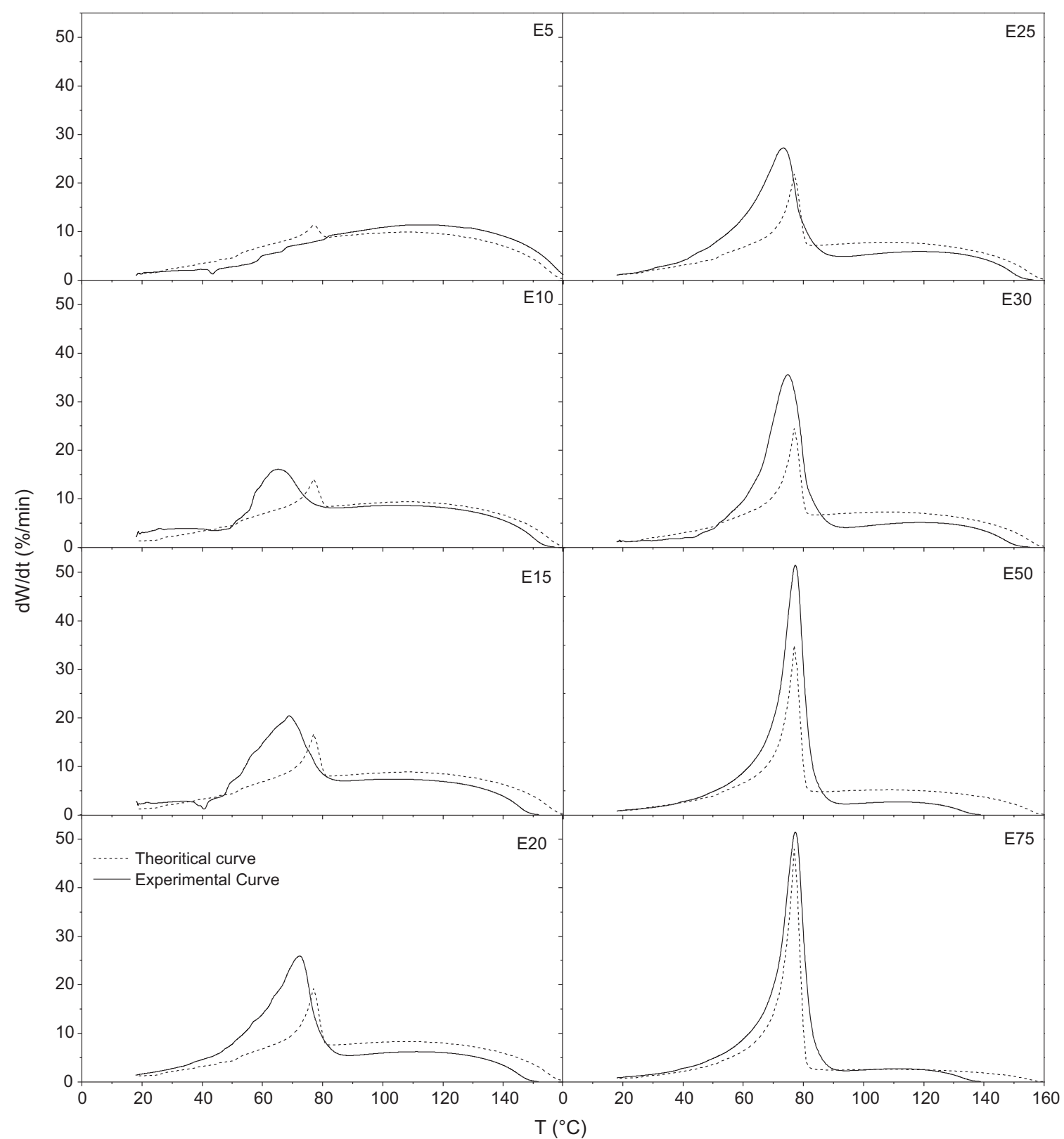

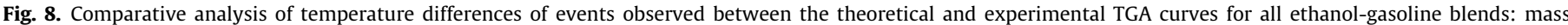
samples of $15 \pm 0.12 \mathrm{mg}$, synthetic air at $100 \mathrm{~mL} / \mathrm{min}$, and heating rate $10{ }^{\circ} \mathrm{C} / \mathrm{min}$.

Table 4

Relative error for weight loss of the ethanol-gasoline blends.

\begin{tabular}{|c|c|c|c|c|c|c|c|c|}
\hline Errors & E5 & E10 & E15 & E20 & E25 & E30 & E50 & E75 \\
\hline Medium Error (\%) & -23.14 & 20.88 & 18.03 & 21.83 & 17.40 & 7.24 & 7.85 & 5.36 \\
\hline Maximum Error (\%) & 1.58 & 50.81 & 48.63 & 48.86 & 45.07 & 39.78 & 28.67 & 14.25 \\
\hline Minimum Error (\%) & -53.40 & 1.58 & -6.08 & 1.80 & 1.41 & -26.88 & -31.19 & -1.86 \\
\hline Temp. max error $\left({ }^{\circ} \mathrm{C}\right)$ & 25 & 25 & 70 & 70 & 75 & 75 & 75 & 85 \\
\hline
\end{tabular}

Note: Temp. max error: is the temperature where de maximum error occurs.

Table 5

Percentages for the interaction of peak temperatures with DTG curves of ethanol-gasoline blends.

\begin{tabular}{|c|c|c|c|c|c|c|c|c|}
\hline Interaction & E5 & E10 & E15 & E20 & E25 & E30 & E50 & E75 \\
\hline Peak temp. theo. $\left({ }^{\circ} \mathrm{C}\right)$ & 77.9 & 77.9 & 77.9 & 77.9 & 77.9 & 77.9 & 77.9 & 77.9 \\
\hline Peak temp. exp. $\left({ }^{\circ} \mathrm{C}\right)$ & nd & 65.3 & 68.8 & 72.5 & 73.4 & 74.8 & 77.4 & 77.9 \\
\hline Interaction (\%) & nd & 16.17 & 11.68 & 6.93 & 5.78 & 3.98 & 0.64 & 0.00 \\
\hline
\end{tabular}

Note: not detectable. 
Table 6

Relative error of activation energy obtained for ethanol-gasoline blends.

\begin{tabular}{|c|c|c|c|c|c|c|c|c|}
\hline Errors & E5 & E10 & E15 & E20 & E25 & E30 & E50 & E75 \\
\hline Medium error (\%) & 1.83 & 19.54 & 21.82 & -110.31 & -50.63 & -58.70 & 1.96 & 26.22 \\
\hline Maximum error (\%) & -88.55 & -103.95 & -149.27 & -291.68 & -313.89 & -366.09 & -52.68 & 9.52 \\
\hline Minimum error (\%) & 69.32 & 73.19 & 68.30 & 34.07 & 28.63 & 56.29 & 49.95 & 40.16 \\
\hline Conversion range to synergy $(\alpha)$ & 0.8 & 0.8 & 0.8 & 0.6 & 0.8 & 0.7 & 0.3 & nd \\
\hline
\end{tabular}

Note: not detectable.

75\% ethanol presents no synergetic interaction with activation energy.

\section{Conclusions}

The thermogravimetric curves of the blends showed profiles that change according to ethanol content, having a profile displacement as the percentage of ethanol increases. Blends of lower content showed similar thermal behavior to E0 gasoline, while blends of higher concentration were similar to ethanol (E100).

The results showed that the thermal decomposition of gasoline and ethanol occurs in only one stage, while blends have two stages of thermal decomposition.

As expected, the thermal characteristics of the blends showed by TG/DTG curves are quite different from those observed in experimental and theoretical volatilization curves obtained for pure ethanol and gasoline samples. The results showed that the synergistic effect of mass thermal decomposition was influenced at $50 \%$ by the blends with low ethanol content, between E10 and E20. They also have a maximum percentage in the peak temperature progress at about $16.17 \%$ for E10 in the DTG curve, which decreases as there is an increase in the blend ethanol content.

The thermal gravimetric analysis technique was improved with the synergy analysis, and the relative error of interaction has shown good results as a tool to evaluate the kinetics of liquid fuels combustion, specifically ethanol-gasoline blends.

\section{References}

[1] U.S. Doe, Annual Energy Outlook 2015 (2015). <http://www.eia.gov/forecasts/ aeo/pdf/0383(2015).pdf >.

[2] C.K. Westbrook, Biofuels combustion, Annu. Rev. Phys. Chem. 64 (2013) 201 219, http://dx.doi.org/10.1146/annurev-physchem-040412-110009.

[3] A. Elfasakhany, Investigations on the effects of ethanol-methanol-gasoline blends in a spark-ignition engine: performance and emissions analysis, Eng. Sci. Technol. Int. J. (2015) 1-7, http://dx.doi.org/10.1016/j.jestch.2015.05.003.

[4] Y. Zhuang, G. Hong, Primary investigation to leveraging effect of using ethanol fuel on reducing gasoline fuel consumption, Fuel 105 (2013) 425-431, http:// dx.doi.org/10.1016/j.fuel.2012.09.013.

[5] L. Sileghem, A. Coppens, B. Casier, J. Vancoillie, S. Verhelst, Performance and emissions of iso-stoichiometric ternary GEM blends on a production SI engine Fuel 117 (2014) 286-293, http://dx.doi.org/10.1016/j.fuel.2013.09.043.

[6] S.M. Sarathy, P. Oßwald, N. Hansen, K. Kohse-Höinghaus, Alcohol combustion chemistry, Prog. Energy Combust. Sci. 44 (2014) 40-102, http://dx.doi.org/ 10.1016/j.pecs.2014.04.003.

[7] J.M. Bergthorson, M.J. Thomson, A review of the combustion and emissions properties of advanced transportation biofuels and their impact on existing and future engines, Renew. Sustain. Energy Rev. 42 (2015) 1393-1417, http:// dx.doi.org/10.1016/j.rser.2014.10.034.

[8] J.E. Anderson, D.M. Dicicco, J.M. Ginder, U. Kramer, T.G. Leone, H.E. RaneyPablo, T.J. Wallington, High octane number ethanol-gasoline blends: quantifying the potential benefits in the United States, Fuel 97 (2012) 585594, http://dx.doi.org/10.1016/j.fuel.2012.03.017.

[9] J. Lane, Biofuels mandates around the world (2015) 1-10. <http://www. biofuelsdigest.com/bdigest/2014/12/31/biofuels-mandates-around-theworld-2015/> (accessed January 20, 2016)

[10] L.R. Cancino, M. Fikri, A.A.M. Oliveira, C. Schulz, Ignition delay times of ethanol-containing multi-component gasoline surrogates: shock-tube experiments and detailed modeling, Fuel 90 (2011) 1238-1244, http://dx. doi.org/10.1016/j.fuel.2010.11.003.
[11] L.M. Rodríguez-Antón, M. Hernández-Campos, F. Sanz-Pérez, Experimental determination of some physical properties of gasoline, ethanol and ETBE blends, Fuel 112 (2013) 178-184, http://dx.doi.org/10.1016/ j.fuel.2013.04.087.

[12] S. Jain, M.P. Sharma, Application of thermogravimetric analysis for thermal stability of Jatropha curcas biodiesel, Fuel 93 (2012) 252-257, http://dx.doi. org/10.1016/j.fuel.2011.09.002.

[13] M.V. Kok, E. Özgür, Thermal analysis and kinetics of biomass samples, Fuel Process. Technol. 106 (2013) 739-743, http://dx.doi.org/10.1016/ j.fuproc.2012.10.010.

[14] C.C. Conconi, P.M. Crnkovic, Thermal behavior of renewable diesel from sugar cane, biodiesel, fossil diesel and their blends, Fuel Process. Technol. 114 (2013) 6-11, http://dx.doi.org/10.1016/j.fuproc.2013.03.037.

[15] G. Dwivedi, M.P. Sharma, Experimental investigation on thermal stability of Pongamia Biodiesel by thermogravimetric analysis, Egypt. J. Petrol. 25 (2015) 8-13, http://dx.doi.org/10.1016/j.ejpe.2015.06.008.

[16] S.A. El-Sayed, M.E. Mostafa, Pyrolysis characteristics and kinetic parameters determination of biomass fuel powders by differential thermal gravimetric analysis (TGA/DTG), Energy Convers. Manage. 85 (2014) 165-172, http://dx. doi.org/10.1016/j.enconman.2014.05.068.

[17] Y. Luo, L. Zhu, J. Fang, Z. Zhuang, C. Guan, C. Xia, X. Xie, Z. Huang, Size distribution, chemical composition and oxidation reactivity of particulate matter from gasoline direct injection (GDI) engine fueled with ethanolgasoline fuel, Appl. Therm. Eng. 89 (2015) 647-655, http://dx.doi.org/10.1016/ j.applthermaleng.2015.06.060.

[18] M.V. Gil, D. Casal, C. Pevida, J.J. Pis, F. Rubiera, Bioresource technology thermal behaviour and kinetics of coal/biomass blends during co-combustion, Bioresour. Technol. 101 (2010) 5601-5608, http://dx.doi.org/10.1016/j. biortech.2010.02.008.

[19] A.O. Oyedun, C.Z. Tee, S. Hanson, C.W. Hui, Thermogravimetric analysis of the pyrolysis characteristics and kinetics of plastics and biomass blends, Fuel Process. Technol. 128 (2014) 471-481, http://dx.doi.org/10.1016/ j.fuproc.2014.08.010.

[20] H. Liu, W. Liang, H. Qin, Q. Wang, Synergy in co-combustion of oil shale semicoke with torrefied cornstalk, Appl. Therm. Eng. 109 (2016) 653-662, http:// dx.doi.org/10.1016/j.applthermaleng.2016.08.125.

[21] J. Pasqualino, D. Montané, J. Salvadó, Synergic effects of biodiesel in the biodegradability of fossil-derived fuels, Biomass Bioenergy 30 (2006) 874-879, http://dx.doi.org/10.1016/j.biombioe.2006.03.002.

[22] D.D. Rustschev, Application of thermal analysis for investigating liquid fuels, petroleum- and coke-chemical products, Thermochim. Acta 168 (1990) 261271, http://dx.doi.org/10.1016/0040-6031(90)80645-F.

[23] R.C. Mackenzie, Nomenclature in thermal analysis, part IV, Thermochim. Acta 28 (1979) 1-6.

[24] C. Buratti, S. Mousavi, M. Barbanera, E. Lascaro, F. Cotana, M. Bufacchi, Bioresource technology thermal behaviour and kinetic study of the olive oil production chain residues and their mixtures during co-combustion, Bioresour. Technol. 214 (2016) 266-275, http://dx.doi.org/10.1016/j. biortech.2016.04.097.

[25] M. Hu, Z. Chen, S. Wang, D. Guo, C. Ma, Y. Zhou, J. Chen, M. Laghari, S. Fazal, B. Xiao, B. Zhang, S. Ma, Thermogravimetric kinetics of lignocellulosic biomass slow pyrolysis using distributed activation energy model, Fraser-Suzuki deconvolution, and iso-conversional method, Energy Convers. Manage. 118 (2016) 1-11, http://dx.doi.org/10.1016/j.enconman.2016.03.058.

[26] K. Jayaraman, I. Gokalp, Gasification characteristics of petcoke and coal blended petcoke using thermogravimetry and mass spectrometry analysis, Appl. Therm. Eng. 80 (2015) 10-19, http://dx.doi.org/10.1016/j. applthermaleng.2015.01.026.

[27] E.C.F. Alexandre, E.V. Silveira, C.F.D.S. Castro, J.F. Sales, L.C.S. De Oliveira, L.H. Viana, L.C.A. Barbosa, Synthesis, characterization and study of the thermal behavior of methylic and ethylic biodiesel produced from tucumã (Astrocaryum huaimi Mart.) seed oil, Fuel 161 (2015) 233-238, http://dx.doi. org/10.1016/j.fuel.2015.08.062.

[28] S. Deng, X. Wang, H. Tan, H. Mikulčić, F. Yang, Z. Li, N. Duić, Thermogravimetric study on the Co-combustion characteristics of oily sludge with plant biomass, Thermochim. Acta 633 (2016) 69-76, http://dx.doi.org/10.1016/j. tca.2016.03.006.

[29] H.K. Imdadul, H.H. Masjuki, M.A. Kalam, N.W.M. Zulkifli, A. Alabdulkarem, M. M. Rashed, A.M. Ashraful, Influences of ignition improver additive on ternary (diesel-biodiesel-higher alcohol) blends thermal stability and diesel engine 
performance, Energy Convers. Manage. 123 (2016) 252-264, http://dx.doi.org/ 10.1016/j.enconman.2016.06.040.

[30] M.A. Varfolomeev, A. Galukhin, D.K. Nurgaliev, M.V. Kok, Thermal decomposition of Tatarstan Ashal'cha heavy crude oil and its SARA fractions, Fuel 186 (2016) 122-127, http://dx.doi.org/10.1016/j.fuel.2016.08.042.

[31] S. Vyazovkin, C.A. Wight, Isothermal and nonisothermal reaction kinetics in solids: in search of ways toward consensus, J. Phys. Chem. A 101 (1997) 82798284, http://dx.doi.org/10.1021/jp971889h.

[32] S. Vyazovkin, C.A. Wight, Kinetics in solids, Annu. Rev. Phys. Chem. 48 (1997) 125-149, http://dx.doi.org/10.1146/annurev.physchem.48.1.125.
[33] S. Vyazovkin, A.K. Burnham, J.M. Criado, L.A. Pérez-Maqueda, C. Popescu, N. Sbirrazzuoli, ICTAC Kinetics Committee recommendations for performing kinetic computations on thermal analysis data, Thermochim. Acta 520 (2011) 1-19, http://dx.doi.org/10.1016/j.tca.2011.03.034.

[34] X. Ren, J. Meng, A.M. Moore, J. Chang, J. Gou, S. Park, Thermogravimetric investigation on the degradation properties and combustion performance of bio-oils, Bioresour. Technol. 152 (2014) 267-274, http://dx.doi.org/10.1016/j. biortech.2013.11.028. 